\title{
Estimates of Factors Affecting Economic Growth in the Agricultural Sector in the Development Plan
}

\author{
Naftaly Gisore Mose \\ School of Economics, University of Eldoret, Eldoret, Kenya
}

Email address:

ngmoce a uoeld.ac.ke

To cite this article:

Naftaly Gisore Mose. Estimates of Factors Affecting Economic Growth in the Agricultural Sector in the Development Plan. International Journal of Environmental Chemistry. Vol. 3, No. 2, 2019, pp. 59-64. doi: 10.11648/j.ijec.20190302.12

Received: March 10, 2019; Accepted: April 29, 2019; Published: December 24, 2019

\begin{abstract}
Agricultural sector contribute about 36\% of the East African Community's Gross Domestic Product (World Bank, 2009), 80 per cent of the populace depend on agriculture directly and indirectly for food, employment and income, while about 40 million people in EAC (East African Countries) suffer from hunger and the agricultural sector still retains a lot of untapped potential, specifically for commercial farming. However, economic growth target for agriculture sector can be achieved by stimulating three factors; capital, labor and total productivity of capital and labor through R\&D. This study applied panel random effect model on EAC countries data, 2000-2014. Random effects regression results showed that all explanatory variables had a significant and positive relationship with the dependent variable. From the findings the study recommends: R\&D to be allocated more funds; more research scientists and agricultural labourers to be employed; R\&D based knowledge to be disseminated to the public through publications; firms to train agricultural labourers on how new technologies are being used and also to allocate them duties and responsibilities that match their skills and that agricultural capital costs be subsidised.
\end{abstract}

Keywords: Agricultural Sector Growth, Labour, Capital, Research and Development, EAC, Economic Growth

\section{Introduction}

Economic planning, the process by which key economic decisions in the long-term are made or accomplished by directing and controlling the economic development plans as formulated in the country's economic plans. Further, Sectoral planning is performed on the quantitative variables influencing economic growth tools, resources and economic potentials of each section, (macro and sector levels), in planning and formulation of in order to achieve development goals at the macro level. However, studies have shown that the development plan tools have significant effect on GDP growth of the agricultural sector and labor productivity in agriculture. Also, key finding is that there is a direct relationship with investment of the public planning $[5,9]$.

Further, Matahir took a different stand on his study on the role of agriculture on economic growth and how it interplays with other sectors in the economy. Time series Johansen cointegration techniques was employed to investigate the non-causality relationship between agriculture and other economic sectors of Tunis. From their findings, it was posited that, policy makers should see agricultural sectors as vital tools in their analysis of inter-sectorial growth policies [11].

Therefore, the actual investment in the agricultural sector are not limited to the tools of production, machinery and buildings; actually in the agricultural sector part of the earth, trees and livestock units are considered a type of capital. However, share of land and living capital (trees and livestock production) lies in value added of agricultural sector and it is not just the result of employing labor and physical capital.

Agriculture is known to be an extended age practice in the third world and developing nations. The importance of agricultural development to socio-economic growth and development in many third world countries is keen on their transition to economic prosperity. Nevertheless, the trend of agriculture in Africa over the past decades has not been favorable [5]. The growth of agriculture in the sixties and seventies has been experiencing a downward trend.

Agriculture takes a large share of National Income throughout East Africa. According to FAO and World Bank development Indicators, agriculture accounts for $43 \%$ of the total GDP in the region. In Tanzania and Burundi agricultural 
share of GDP exceeds 50\% and in Uganda and Rwanda it is about $50 \%$. Only in Kenya, it contributes less than $30 \%$ because Kenya's structural transformation towards a less agricultural-based economy is more advanced than in other countries in the sub-region.

Table 1. Agricultural Growth rate for specific county, 1993-2003.

\begin{tabular}{llll}
\hline Country & Production & Area & Yield \\
\hline Burundi & -0.09 & 0.31 & -0.40 \\
Kenya & 1.87 & 0.45 & 1.41 \\
Rwanda & 7.86 & 6.43 & 1.30 \\
Tanzania & 1.73 & 0.47 & 1.25 \\
Uganda & 3.31 & 2.31 & 0.98 \\
\hline
\end{tabular}

Source: [5]

Labour productivity in East Africa has declined substantially due to labour contraction especially in Kenya and Tanzania. However, it has recovered substantially in Rwanda and Uganda. Given these trends the average yield for East Africa's major crops currently fall well below those elsewhere in Africa and even further below global levels. It is only for cassava, beans, coffee and tea where east Africa yields compares favourably with average African and global levels. These trends in productivity growth have translated into poor overall agricultural growth rates in individual countries in East Africa and for the region as a whole.

NEPAD estimates that to achieve the MDG of halving poverty by 2015 , African countries must register overall economic growth rates in excess $6 \%$ per year over the next 12 years. In economies dominated by agriculture such as those of east Africa, achieving such GDP growth rates means generating rapid growth in agriculture. But the various agriculture sub sectors probably make different contributions to overall economic growth $[15,20]$.

Common capital goods such as machines and means of transport and even labour are products for which there is rivalry; they cannot be used at the same time for different purposes. Knowledge, however, is a product that is nonrivalry. This means that a company's use of the product (knowledge) does not diminish any other company's use of the product $[8,9]$. However, knowledge is often, also non excludable. A company that has invested in $R \& D$ to acquire new knowledge may find it difficult to prevent other companies from using this new knowledge unless it is patented thus knowledge becomes "a public good". It is also highly unlikely that a company will itself have the expertise required to utilise all the knowledge generated by the R\&D concerned. These factors explain how R\&D can lead to spillovers to other companies and can lead to rising returns to scale which otherwise contradict the neo-classical theory.

Arrow model regarded learning by doing as endogenous in the growth process. The theory hypothesised that at any moment of time, new capital goods incorporate all the knowledge then available based on accumulated experience, but once built, their productive deficiencies cannot be changed by subsequent learning. The theory showed that if the stock of labour is held constant, growth ultimately comes to a halt because socially very little is invested and produced [9]. This was supported by Segura \& Rodriguez, that learning is a product of experience (doing) that takes place during activity, since it usually occurs through the attempt to solve a problem [21]. Rotheli also supported this theory by saying that the observation by Arrow proved the capability of workers to improve their productivity by regularly repeating the same type of action. The increased productivity is achieved through practice, self perfection and minor innovations [22]. However, Romer criticised this model by saying that for technical reasons, the fact that this model could lead to sustained endogenous growth was not emphasised [21].

Some researchers conducted research on the effect of R\&D and other areas related to $\mathrm{R} \& \mathrm{D}$ on economic growth in different countries and regions. All of them have come up with different results hence they have been inconclusive.

Sertoğlu et al. examined the impact of agricultural sector on the economic growth of Nigeria, using time series data from 1981 to 2013. Findings revealed that real gross domestic product, agricultural output and oil rents have a long-run equilibrium relationship. Vector error correction model result shows that, the speed of adjustment of the variables towards their long run equilibrium path was low, though agricultural output had a positive impact on economic growth [20].

Gutierrez \& Gutierrez analysed the new growth theory framework and using panel co-integration techniques; the effect of agricultural international technological spillovers on total factor productivity growth for a sample of 47 countries during the period 1970-1992. They concluded that the United States R\&D capital stock has the strongest effect on total factor productivity of its trade partners. A $1 \%$ increase in the R\&D capital stock increases total factor productivity by an average of $0.1 \%$ for the full sample of 47 countries [6].

Bronzini \& Paolo studied the long-run relationship between regional total factor productivity, public infrastructure, human capital, and R\&D in Italy during the period 1980-2001; R\&D has a positive effect on productivity whereas R\&D stock in one region affects productivity levels in nearby regions. This showed that geographical location is relevant for R\&D spillovers [4].

Kim analysed the effect of R\&D activities on economic growth for Korea by using R\&D based Cobb-Douglas production function and the data for the period 1976-2009. According to his empirical findings, traditional production factors i.e labour and capital contributed to economic growth by approximately $65 \%$. The contribution of R\&D stocks on economic growth was approximately $35 \%$. Detailed analysis showed that the contribution of private and public R\&D stocks on economic growth is $16 \%$ and $19 \%$ respectively [8].

Pardy et al. studied the effect of R\&D in the agricultural sector in Asia and Pacific region for the period 1960-2009. They found that countries with larger agricultural economies are likely to invest more in agricultural $R \& D$ and those with smaller agricultural economies are likely to invest less in agricultural R\&D simply because of congruent effect [13]. 


\section{Model}

Endogenous Growth Theory incorporates this 'feedback loop' of technological growth affecting the growth rate of capital, which affects technological advancements. These theories examine the reasons for the differences in GDP growth rates of different countries, the effectiveness of various measures of the state's scientific, technical and industrial policies, as well as the impact of the processes of international integration and trade on economic growth [12]. Technical change is no longer regarded as unexplainable and due to chance as in neo-classical theory, but in endogenous theories becomes itself a variable which can be influenced by policy decisions and should now be included within production functions, alongside the conventional inputs of labour and capital. On the empirical side, endogenous growth models become an alternative to the Solow model, when this fails to explain cross country differences, mainly related to the concept of convergence [2]. Another frequent critique concerns the cornerstone assumption of diminishing returns to capital $[2,16]$.

LLC Panel unit root test was conducted to avoid analysing non stationary data at level which in turn could lead to spurious results or results that do not make sense. Data found to be non-stationary at level were differenced for stationarity to be achieved. Stationary data were then analysed because the results were now sensible. Levin, Lin and Chu [12] developed a unit root test for panel data. When the linear combination of the two variables is I (0), then the variables are said to be co integrated. Differencing leads to lose of long run relationship between variables and so co integration test is being conducted to check whether the variables have got long run relationship or not. Pedroni [14] developed a residual-based panel co integration test statistics based on within dimension and between- dimensions. To ascertain whether to employ fixed effects model or random effects model, the study conducted Hausman Test which was developed by Hausman [7]. The test basically tries to establish whether the error terms are correlated with the regressors, with the null hypothesis stating absence of such correlation.

The basic panel regression equation that was used to investigate the relationship between $R \& D$ and agricultural sector growth was therefore of the type:

$$
\begin{gathered}
\ln _{i, t}=\beta_{0}+\beta_{1} \operatorname{lnak}_{i, t-1}+\beta_{2} \operatorname{lnal}_{i, t-1}+\beta_{3} \operatorname{lnar}_{i, t-1} \\
+\mu_{i}+v_{t}+\varepsilon_{i, t}
\end{gathered}
$$

In y -Agricultural Sector Growth, In al - Agricultural labour, In ak -Agricultural capital,

ln ar - Agricultural Research Expenditure, $\Delta$ - First difference operator

$\mu_{\mathrm{i}}-$ county fixed effects $\mathrm{v}_{\mathrm{t}}-$ time fixed effects $\varepsilon_{\mathrm{i}, \mathrm{t}}-$ the error term and the subscripts $i$ and $t$ represent county and time period respectively.

Research and development leads to; new and improved products, processes and markets, and increase in knowledge which has got spill over effects hence leading to agricultural sector growth. R\&D in the agricultural sector was measured by expenditure on agricultural R\&D. Also, Availability of agricultural capital leads to increased agricultural productivity because it augments labour in the production process. Agricultural capital was measured through the use of expenditure on inputs. Further, agricultural labour leads to agricultural sector growth because it is a factor of production in the production process in agriculture hence increases the productivity of the agricultural sector. Agricultural labour was measured through the use of the actual number of people employed in the agricultural sector in these countries. Data was collected from Agricultural Science and Technology Indicators, World Bank and from the specific countries Statistical Abstracts. This expenditure was measured in US dollars.

There are some econometric problems which when present in the regression results makes the parameter estimates biased and may lead to biased estimations. These are heteroscedasticity, autocorrelation and multicollinearity. Therefore tests for the mentioned problems were conducted so as to effect the appropriate corrections.

\section{Results}

Table 2. Results of Descriptive Analysis.

\begin{tabular}{llllll}
\hline Variable & N & Mean & Std. & Min & Max \\
\hline $\ln y$ & 75 & 18.8 & 3.0 & 9.2 & 25.0 \\
ln $a r$ & 75 & 17.5 & 1.2 & 14.2 & 18.9 \\
In $a k$ & 75 & 7.8 & 2.0 & 4.1 & 9.9 \\
ln al & 75 & 8.2 & 0.6 & 7.4 & 9.3 \\
\hline
\end{tabular}

Notes: $* * *$ denotes significant at 1 percent, $* *$ significant at 5 percent, and $*$ significant at 10 percent

ln y -Agricultural Sector Growth, In al - Agricultural labour, ln ak Agricultural capital,

ln ar - Agricultural Research Expenditure, $\Delta$ - First difference operator

From Table 2 above, the mean of agricultural output growth is 18.8 This means that on average, agricultural output growth in EAC countries for the period 2000-2014 was in range of 18.8. The standard deviation is 3.0 which means that for the period 2000-2014, agricultural output growth in EAC deviated from the mean by 3.0. The minimum of agricultural output growth in EAC for the period 2000-2014 was 9.2 while the maximum of agricultural output growth for the same period was 25.0. This means that the range of agricultural output growth in EAC for the period 2000-2014 was 15.8. Further, for the case of agricultural R\&D expenditure, agricultural capital and agricultural labour, the mean was $17.5,7.8$ and 8.2 , respectively. Further for the same period the standard deviation was 1.2, 2.0 and 0.6 , respectively. Showing how the main variables deviated from the average.

Correlation is the measure of the degree of association between variables and the correlation coefficient ranges from -1 to +1 with closeness to absolute 1 showing a strong correlation between the study variables. Table 3 below shows the correlation results. 
Table 3. Results of Correlation Matrix.

\begin{tabular}{llllll}
\hline & $\ln \boldsymbol{y}$ & $\ln \boldsymbol{a} \boldsymbol{r}$ & $\ln \boldsymbol{a r}$ & $\ln \boldsymbol{a k}$ & $\ln \boldsymbol{a l}$ \\
\hline $\ln y$ & 1.000 & & & & \\
$\ln a r$ & $0.364^{* * *}$ & 1.000 & & & \\
$\ln a k$ & $0.497^{* * *}$ & $0.779^{* * *}$ & $0.459^{* * *}$ & 1.000 & \\
$\ln a \mathrm{l}$ & $0.407^{* * *}$ & $0.647^{* * *}$ & $0.231^{* *}$ & $0.813^{* * *}$ & 1.0000 \\
\hline
\end{tabular}

Notes: $* * *$ denotes significant at 1 percent, ${ }^{* *}$ significant at 5 percent, and $*$ significant at 10 percent

ln $y$-Agricultural Sector Growth, In al - Agricultural labour, ln ak Agricultural capital,

ln ar - Agricultural Research Expenditure, $\Delta$ - First difference operator

From Table 3 above, the correlation coefficient between agricultural $R \& D$ expenditure and agricultural output growth is 0.364 . The positive relationship is because agricultural R\&D expenditure leads to more and serious research on the agricultural sector which in turn leads to better techniques of production in the agricultural sector hence increased agricultural output. Agricultural capital and agricultural output growth has a correlation coefficient of 0.497 . The positive relationship is because agricultural capital helps in facilitating the production process in the agricultural sector hence increased agricultural output. In the case of agricultural labour and agricultural output growth, the correlation coefficient is 0.407 . The positive relationship is because agricultural labour plays the role of operating agricultural capital and offering other agricultural related services like planting and weeding hence increased agricultural output.

LLC panel unit root was applied on the regression model to determine whether the variables were stationary at level and regression result presented on Table 4.

Table 4. Results of the Panel Unit Root Tests Using LCC.

\begin{tabular}{llllll}
\hline Variable & Level & P-Value & Variable & Level & P-Value \\
\hline $\ln y$ & -4.109 & 0.000 & & & \\
$\ln a k$ & 0.664 & 0.747 & $\Delta \ln a k$ & -1.914 & 0.000 \\
$\ln a l$ & -3.067 & 0.000 & & & $\mathrm{I}(0)$ \\
$\ln$ ar & -1.635 & 0.051 & $\Delta \ln a r$ & -5.618 & $\mathrm{I}(0)$ \\
\hline
\end{tabular}

Notes: $* * *$ denotes significant at 1 percent, $* *$ significant at 5 percent, and $*$ significant at 10 percent

ln $y$-Agricultural Sector Growth, In al - Agricultural labour, In ak -Agricultural capital,

ln ar - Agricultural Research Expenditure, $\Delta$ - First difference operator

From Table 4 above, agricultural output growth and agricultural labour were found to be stationary at level and statistically significant at $1 \%$ level while the remaining variables, that is, agricultural $R \& D$ expenditure agricultural capital were found to be non stationary but became stationary after first differencing. Since the dependent variable (agricultural output growth) was found to be stationary at level, conducting co integration test was impossible because the dependent variable and the independent variables were now not integrated of the same order.

The panel random effect estimation technique that was applied and the findings presented in Table 5 below.

Table 5. Result of Panel Random Effects Regression Model.

\begin{tabular}{lllll}
\hline Variable & Coefficient & Standard error & z- Statistics & P-value \\
\hline In $a k$ & $0.122^{* *}$ & 0.0576 & 2.11 & 0.035 \\
ln al & $0.161^{* * *}$ & 0.0595 & 2.71 & 0.007 \\
Aln $a r$ & $0.853^{* *}$ & 0.3969 & 2.15 & 0.032 \\
Cons & 0.298 & 0.6071 & 0.49 & 0.627 \\
LM Test & & $\mathrm{Prob}>\mathrm{F}=0.097$ \\
Breusch - Pagan Test & & $\mathrm{Prob}>\mathrm{F}=1.00$ \\
Pesaran CD & & $\mathrm{Pr}=0.31$ \\
Ramsey-Reset Test & & $\mathrm{Pr}=0.14$ \\
Hausman test & & $\mathrm{Pr}=0.28$ \\
F statistics & & $\mathrm{P}(\mathrm{F})=0.00$ \\
Goodness of Fit Test & $\mathrm{R}^{2}=0.58$ & Adjusted $\mathrm{R}^{2}=0.57$ \\
\hline
\end{tabular}

Notes: $* * *$ denotes significant at 1 percent, $* *$ significant at 5 percent, and $*$ significant at 10 percent

ln $y$-Agricultural Sector Growth, In al - Agricultural labour, $\ln a k$ Agricultural capital,

ln ar - Agricultural Research Expenditure, $\Delta$ - First difference operator

For the case of agricultural capital, the coefficient is 0.12 and statically significant at 5\% level of significance. This implies that a one percent increase in agricultural capital leads to a $0.12 \%$ increase in agricultural sector growth (output). The result is positive and conforms to the conventional view. This could be because agricultural capital helps in faster facilitation of agricultural activities for example in faster tilling of land, faster planting, faster weeding, faster harvesting of crops, faster milking of cows, faster spraying of domestic animals and faster milling of grains hence helps to increase/improve the quality and quantity of agricultural products. In addition, it could be because transportation of the agricultural products or agricultural raw materials is made easier and faster to the markets, stores and factories. There could also be reduced wastage of agricultural products which may lead to increased productivity as raw materials could be easily transported to the factories for processing. The finding of this study on the effect of agricultural capital on agricultural sector growth is in agreement to the finding of Kim [8].

For the case of agricultural labour, the coefficient is 0.16 and statically significant. The positive relationship may be attributed to the presence of a healthy and energetic agricultural labour force who could actively participate in the various roles assigned to them like driving of tractors for tilling land, planting, weeding and harvesting and this could lead to increased agricultural productivity. The other factor that could have contributed to this positive relationship between agricultural labour force and agricultural output growth could be a good work environment for the agricultural labour force through better wages, provision of security and working tools, appropriate working hours, 
proper laws and regulations that were protecting their rights and which were being implemented and these could have prevented things like strikes and go-slows and instead boosted their morale in their work and hence increased agricultural output. In addition, the positive coefficient could have been because of the presence of trained, skilled and experienced agricultural labour force which implies that they had the capability to use the farm tools and equipment and were also well versed with the way the farm tools and equipments were being used in the production process and hence led to increased agricultural output. Further, the above finding agrees with the result of $\operatorname{Kim}[8,20]$.

From the regression results, the coefficient of agricultural R\&D expenditure is 0.85 and statically significant at $5 \%$. The endogenous growth theory says that R\&D leads to increase in the stock of knowledge which in turn has got spill over effects hence leads to economic growth. This positive relationship could be because allocating funds for agricultural research leads to increased agricultural research which causes increased knowledge about high yielding crops, the invention of drought resistant crops which helped in preventing crop failures in the event of a drought, better ways of improving soil fertility which leads to increased yields, introduction of advanced machines in production which made the production process to go faster hence high quality and quantity of products within a short period of time. These advanced machines may include machines for tilling land like tractors, milking machines, harvesting machines and planting machines. Agricultural research and development could have also led to the discovery of crop and livestock diseases, what causes them, how they can be prevented and even a solution should they occur. This boosts crop productivity and hence increased agricultural growth. The positive and significant effect of agricultural R\&D expenditure could have been as a result of proper dissemination of knowledge generated through agricultural R\&D and thus increasing agricultural productivity in EAC. The above finding agrees with the previous studies of Gutierrez \& Gutierrez; and Pardy et al. $[6,13,20]$.

The constant is 3.0 , this implies that without the variables like agricultural R\&D expenditure and agricultural capital and agricultural labour in the EAC, agricultural output growth remains at the level of 3.0, although the constant variable it remained insignificant during the review period.

The random dynamic regression model passes all the diagnostic tests carried out in this study. In particular, Ramsey RESET test indicates that there is no specification error in the model, LM test statistics shows that there is no serial correlation in the model as well heteroscedasticity is not a problem as shown by the $\mathrm{P}$ value. The estimated coefficient of determination shows that the regressors jointly explain 56 percent of the variation in the dependent variable which means it fits the data well. Finally, Hausman test pointed towards the preferred model as random effect model.

\section{Conclusion}

Already accounting for about $36 \%$ of GDP in the EAC economy, the agriculture sector still retains a lot of untapped potential, specifically for commercial farming. A necessary condition for achieving economic development is high and stable agriculture sector growth. In the EAC's plan, economic growth target for agriculture sector has been determined about 6 percent that it should achieved by stimulating three factors; capital, labour and total productivity of capital and labour through research and development. The positive and statistically significant relationship between agricultural capital, labour and R\&D, and agricultural sector growth implies that farm tools and equipment, means of transportation of agricultural products, labour efficiency, presence of a healthy and energetic agricultural labour and increased agricultural productivity through $\mathrm{R} \& \mathrm{D}$ hence led to increased agricultural output and economic growth in longrun.

\section{Recommendations}

Agricultural capital influenced agricultural sector growth positively and the influence was statistically significant. To accelerate this effect, the governments of EAC states should subsidize the cost of farm tools and equipment and also make loans easily accessible to farmers by lowering the interest rates to enable them acquire agricultural capital. Taxation on agricultural products that serve as raw materials to the agrobased industries should also be lowered to make raw materials easily available to these industries. Agricultural firms should also invest properly on farm tools and equipment and ensure that they are well serviced and maintained as these efforts will make the agricultural sector not to be capital deficient.

Further, agricultural labour was found to influence agricultural sector growth positively and the influence was statistically significant. To enhance this influence, the governments should subsidise health services for easy access and this will make people to be healthy and energetic and hence more productive in the agricultural sector especially the agricultural labour. In addition, the governments should ensure that there are laws in place that protect the rights of workers in terms of their minimum wage rates and the working hours and also ensure that the laws are adhered to and this will make workers productive as strikes and go slows will not be experienced when the laws are adhered to.

Lastly, R\&D funding should be increased every financial year to facilitate agricultural R\&D. In addition, more agricultural research scientist should be trained and employed for serious agricultural research to be carried out. Also, the government should do more in disseminating the research result to farmers and agricultural institutions. 


\section{References}

[1] Arrow, K. J. (1962). Economic Welfare and the Allocation of Resources for Invention. In K. Arrow (Ed.) The Rate and Direction of Inventive Activity: Economic and social Factors (pp. 609-626). Princeton University Press.

[2] Barro, R., \& Sala-i, M. X. (2 $2^{\text {nd }}$ ed.) (2003). Economic Growth. Cambridge, MIT press.

[3] BreuschT., and Pagan A. (1980). The Langrange Multiplier Test and Its Applications to Model Specification in Econometrics. Review of Economic Studies, No. 47, 239-253.

[4] Bronzini, R., \& Paolo, P. (2006). Determinants of Long-Run Regional Productivity with Geographical Spillovers: The Role of R\&D, Human Capital and Public Infrastructure. Regional Science and Urban Economics, Vol. 2, No. 39, 187-199.

[5] FAO. (2006), Prospect for Food, Nutrition, Agriculture and Major Commodity Groups, Being an Interim Report on World Agriculture Towards 2030/2050. Rome: FAO.

[6] Gutierrez, L., \& Gutierrez, M. (2005). International R\&D Spillovers and Productivity Growth in the Agricultural Sector: A Panel Cointegration Approach. Department of Agricultural Economics: University of Sassasi, Italy.

[7] Hausman J. (1978). Specification Tests in Econometrics. Econometrica, No. 46, 1251-1271.

[8] Kim, L. (2009). The Economic Growth Effect of R\&D Activity in Korea. Korea and the World Economy, Vol. 1, No. $12,25-44$.

[9] Khaledi, K., \& Shirazi, A. (2015). Estimates of Factors Affecting Economic Growth in the Agricultural Sector in the Fifth Development Plan of Iran (Emphasis on Investment). World Applied Sciences Journal, 22 (10): 1492-1499.

[10] Levin, A., Lin, C., \& Chu, C. (2002). Unit Root Tests in Panel Data: Asymptotic and Finite-Sample Properties. Journal of Econometrics, 108, 1-24.
[11] Matahir, H. (2012), the empirical investigation of the nexus between agricultural and industrial sectors in Malaysia. International Journal of Business and Social Science, 3 (8), 225-230.

[12] Ntibagirirwa, S. (2014). Philosophical Premises for African Economic Development Sen's Capability Approach. Globethics net Theses, 7, Geneva.

[13] Pardy, P. G, Kang M, \& Elliott H. (2012). The Structure of Public Support for National Agricultural Research Systems: A Political Economy Perspective. Agricultural Economics, Vol. 4 No. 3.

[14] Pedroni, P. (1999). Crucial Values for Cointegration Tests in Heterogenous Panels with Multiple Regressors. Oxford Bulletin of Economics and Statistics, No. 61, 653-670.

[15] Pesaran, M. H., \& Toseti, E. (2011). Weak and Strong CrossSectional Dependence and Estimation of Large Panels. The Econometric Journal, No. 14, 45-90.

[16] Romer, P. (1986). Increasing Returns and Long Run Growth. Journal of Political Economy, No. 94: 102-37.

[17] Romer, P. (1994). The Origins of Endogenous Growth, Journal of Economic Perspectives, No. 8: 3-22.

[18] Romer, D. H. (2001). Advanced Macroeconomics. Berkeley, the McGraw-Hill Co. Inc.

[19] Rotheli, T. F. (1993). Exogenous and Endogenous Growth, Journal of Political Economy, No. 44:1-10

[20] Sertoğlu, K., Ugural, S., \& Beku, V (2017). The Contribution of Agricultural Sector on Economic Growth of Nigeria. International Journal of Economics and Financial Issues, 7 (1), 547-552.

[21] Segura J, \& Rodriguez B. (2004). An Eponymous Dictionary of Economics: A Guide to Laws and Theories Named after Economists, Edward Elgar Publishing Limited: Chetanham.

[22] Wooldridge, J. (2002). Econometric Analysis of Cross Section and Panel Data, $2^{\text {nd }}$ Edition. The MIT Press: London. 